\title{
Consumption Pattern of Energy Drinks by University of Ibadan Students and Associated Health Risks Factors
}

\author{
Oladejo Thomas Adepoju*, Victoria Oluwakemi Ojo \\ Department of Human Nutrition, Faculty of Public Health, College of Medicine, University of Ibadan, \\ Ibadan, Nigeria \\ Email: tholadejo@yahoo.com
}

Received 30 September 2014; revised 26 October 2014; accepted 15 November 2014

Copyright (C) 2014 by authors and Scientific Research Publishing Inc.

This work is licensed under the Creative Commons Attribution International License (CC BY). http://creativecommons.org/licenses/by/4.0/

\section{Open Access}

\section{Abstract}

Energy drinks are non alcoholic, carbonated beverages claimed to give extra burst of energy for daily obligation. They contain some form of legal stimulants and vitamins which are meant to give consumers short term boost in energy and increase mental alertness. Energy drinks enjoy patronage especially among higher institution students in Nigeria, but little is known about the consumption pattern and possible health risks to consumers. This study was carried out to determine the contribution of four commonly consumed energy drinks to energy intake of University of Ibadan students and the associated health risk factors. A descriptive cross-sectional survey of energy drinks consumption was carried out using a four-stage systematic random sampling technique to select 307 students from six out of nine halls of residence for Undergraduates and the two Postgraduate halls. A validated semi-structured, self-administered questionnaire was used to collect information on socio-demographic characteristics, consumption pattern and frequency, and factors influencing consumption of energy drinks. Samples of the four most commonly consumed energy drinks by the students (Power Horse, Emerge, Red Bull and Matador brands) were purchased from different stores within and around the University of Ibadan campus. Composite samples of all the four energy drinks (with at least six months expiration date) were analysed for physicochemical characteristics, gross energy, minerals and B-vitamins content in triplicate using standard methods of AOAC. Data were analysed using descriptive statistics and one way ANOVA, and level of significance set at $p<0.05$. Respondents mean age was $23.1 \pm 4.6$ years, $79.2 \%$ were undergraduates and $51.1 \%$ were female. Majority $(74.6 \%)$ of respondents had ever taken energy drinks prior to the study, $42.4 \%$ reported consuming at least one can in a week, and $52.1 \%$ consumed 1 can at a sitting. Reasons for consumption included to increase: energy (48.2\%), mental alertness $(18.6 \%)$ and athletic performance $(9.5 \%)$. Reported side effects were: insomnia $(14.0 \%)$, frequent urination $(12.2 \%)$, dehydration $(11.3 \%)$, anxiety $(9.1 \%)$, heart palpitation $(3.5 \%)$. Frequency of consumption was significantly associated with gender $(p<0.05)$. Titratable acidity, total

\footnotetext{
"Corresponding author.
}

How to cite this paper: Adepoju, O.T. and Ojo, V.O. (2014) Consumption Pattern of Energy Drinks by University of Ibadan Students and Associated Health Risks Factors. Food and Nutrition Sciences, 5, 2209-2216. 
solids and pH of energy drinks ranged between $7.57 \pm 0.60-8.28 \pm 0.08,7.57 \pm 0.60-11.42 \pm 0.31$, and $3.36 \pm 0.08-3.81 \pm 0.12$ respectively. Glucose, sucrose, and gross energy content ranged between $7.77 \pm 0.01-7.89 \pm 0.01 \mathrm{~g}, 22.61 \pm 0.07-23.74 \pm 0.09 \mathrm{~g}$, and $43.59 \pm 0.38-48.89 \pm 0.28$ kcal/100g respectively. Few respondents knew about the ingredients and potential health risks associated with energy drink consumption. All the four drinks had acidic $\mathrm{pH}$, hence nutrition education on reduction of energy drink consumption is needed among these students.

\title{
Keywords
}

\author{
Consumption Pattern, Energy Drinks, Nutrient Composition, Calorie Intake
}

\section{Introduction}

Energy drinks are non alcoholic beverages claimed to give extra burst of energy for daily obligation. They are carbonated beverages that contain significant quantities of sugar and caffeine as well as blends of exotic herbal extracts, B vitamins and amino acids meant to give consumers short term boost in energy and increase mental alertness [1] [2].

Energy drinks generally contain methylxanthines (including caffeine [3]), B vitamins, carbonated water, guarana, yerba mate, acai, and taurine, plus various forms of ginseng, maltodextrine, inositol, carnitine, creatine, glucuronolactone, and ginkgo biloba. A common ingredient in most energy drinks is caffeine (often in the form of guarana or yerba mate). They contain about three times the amount of caffeine as cola; for instance, cola contains $35 \mathrm{mg}$ while a monster energy drink contains $120 \mathrm{mg}$. They have been found to improve attention and/or reaction time, increase energy and indices of alertness; and the combination of caffeine and glucose can ameliorate deficits in cognitive performance and subjective fatigue during extended periods of cognitive demand [4] [5].

The sugar content varies among energy drinks but ranges from 21 to 34 grams per 8-ounce can [6]. A teaspoon of sugar weighs about $4 \mathrm{~g}$, so a typical energy drink contains about 13 teaspoons, or just more than $1 / 4$ cup, of sugar [7]. 16 ounce $(454 \mathrm{ml})$ or 24 ounce $(680 \mathrm{ml})$ energy drink contains approximately 60 to 90 grams of sugar, which is two to three times the maximum recommended daily intake $32 \mathrm{~g}$ of 2000 calories. FDA does not recommend a daily allowance for sugar. However, official U.S. guidelines recommend a maximum sugar intake of 32 grams for every 2000 calories, which equates to approximately $7 \%$ to $8 \%$ of the total daily caloric intake [8].

The rate of overweight and obesity have increased worldwide over the last three decades, and while genetic factors may play a part in the development of obesity, the recent dramatic increase in its rate suggests that environmental and behavioural factors have contributed to this problem [9]. Lifestyle and diet changes are the most common culprits, but recent research has proposed that the added sugar content of beverages may play a considerable role in weight gain [10].

Energy drinks are enjoying patronage among adolescents and young adults, especially among University students in Nigeria. The amount of sugar provided in one can (or $500 \mathrm{ml}$ ) of energy drinks is typically about $54 \mathrm{~g}$ [7]. A teaspoon of sugar weighs about $4 \mathrm{~g}$, so a typical energy drinks contains about 13 teaspoons, or just more than $1 / 4$ cup, of sugar [7].

There has been a steady increase in soft drinks and beverages consumption among adolescents and youths globally [11], which has raised a concern about the health effects of soft drinks and beverages. Little is documented on consumption pattern of energy drinks in Nigeria as well as its possible contribution as source of calorie intake of consumers. This study was therefore carried out to determine the nutrient composition and possible contribution of commonly consumed energy drinks to the calorie requirement of the University of Ibadan students.

\section{Materials and Method}

\subsection{Consumption Survey}

A descriptive cross-sectional survey was carried out among University of Ibadan students. A four-stage sam- 
pling technique involving random and systematic random sampling was used to select 307 students from six out of nine halls for Undergraduates and the two Postgraduate halls. A validated semi-structured, self-administered questionnaire was used to collect information on socio-demographic characteristics, consumption pattern and frequency, and factors influencing consumption of energy drinks.

\subsection{Sample Collection and Preparation}

Samples of four commonly consumed energy drinks (Power Horse, Emerge, Red Bull and Matador brands) by students were purchased from different stores within and around the University of Ibadan campus. Composite sample of all the four energy drinks (which had at least six months expiration date) were analysed for physicochemical characteristics (titratable acidity, total solids, $\mathrm{pH}$ ) and energy content using the standard methods of analyses of AOAC (2005) [12]. Heavy metal content of the drinks were determined spectrophotometrically by using Buck 200 atomic absorption spectrophotometer (Buck Scientific, Norwalk United Kingdom (Essien et al., 1992) [13] and compared with absorption of standards of these minerals. All samples were determined in triplicate. The results obtained were analysed using one way analysis of variance (ANOVA), and level of significance was set at $\mathrm{p}<0.05$.

\subsection{Chemical Analyses}

\subsubsection{Determination of Physico-Chemical Parameters}

Total solids of the samples was determined by weighing $5 \mathrm{ml}$ of each sample into a flat bottom metal dish and evaporated to dryness on water bath for about 30 minutes and then transferred to an oven maintained at about $100^{\circ} \mathrm{C}$. After 2.5 hours, the samples were transferred into a dessicator to cool and then weighed. Total acidity was determined by pipetting $5 \mathrm{ml}$ each of energy drink samples into two flasks and $1 \mathrm{ml}$ of the Rosaline working solution to one of the flask and stirred. $1 \mathrm{ml}$ of Phenolphthalein solution was added to the second flask and titrated with $0.1 \mathrm{M}$ sodium hydroxide solution until the colour matched that of the first flask. Then acidity of the drink was calculated as \% citric acid multiplied by the volume of the $0.1 \mathrm{M}$ in ml sodium hydroxide solution required. The $\mathrm{pH}$ of the samples was determined using Jenway $\mathrm{pH}$ meter

Ash of the samples was determined using muffle furnace set at $550^{\circ} \mathrm{C}$ for four hours.

\subsubsection{Determination of Sugars}

One gramme of the sample was weighed into a boiling tube, and $25 \mathrm{ml}$ of hot $80 \%$ ethanol was added and shaken on a vortex mixer. The material was allowed to settle for 30 minutes and then filtered through a Whatman No. 41 filter paper into a beaker. The above steps were repeated again for complete extraction of glucose for 3 times. The extract boiled till the ethanol was evaporated. Ten millilitres of water was added to dissolve the content and transferred into $100 \mathrm{ml}$ volumetric flask. The beaker's content was washed 3 times and added to the volumetric flask and made up with distilled water to $100 \mathrm{ml}$ mark. The sugar (sucrose) was determined by anthrone method, and the absorbance read on spectrophotometer (Spectronic 21D) at a wavelength of $595 \mathrm{~nm}$ against the blank [12]. Glucose was determined by anthrone method by measuring the absorbance of the bluish colour solutions of sample and glucose standards on a Spectronic21D Spectrophotometer at a wavelength of 490 $\mathrm{nm}$ against the blank solution. Gross energy of the samples was determined using ballistic bomb calorimeter (Manufacturer: Cal 2k-Eco, TUV Rheinland Quality Services (Pty) Ltd., South Africa).

\subsubsection{Pantothenic Acid (Vitamin B5) Determination}

Standard solution of sample was prepared by dissolving $1 \mathrm{~g}$ of sample in a $250 \mathrm{ml}$ volumetric flask with distilled water. The solution was filtered through whatman No. 42 filter paper into a 100 ml volumetric flask. 5 ml of aliquot of the sample filtrate was pipette into a $2 \mathrm{ml}$ beaker, $5 \mathrm{ml}$ potassium bromide (12\%), and $10 \mathrm{ml}$ of $\mathrm{KMnO}_{4}$ were added and mixed thoroughly. The mixture was boiled for 10 minutes. The hot solution was cooled in ice for $5 \mathrm{~min}$ and $20 \%$ freshly prepared $\mathrm{H}_{2} \mathrm{SO}_{3}$ was added drop wise to decolonize the excess $\mathrm{KMnO}_{4}$ to colourless solution. Ten millilitres of 2,4-dinitrophenyl hydrazine (5 g/l) was added, mixed thoroughly and heated for 15 minutes and then cooled to room temperature. The yellow precipitate obtained was dried for 30 minutes in an oven at $100^{\circ} \mathrm{C}$. The dry precipitate was dissolved in hot pyridine solution and mixed thoroughly to homogenous suspension. The suspension was filter thorough a Whatman No. 42 filter paper into a 50 ml volumetric flask and made up to mark with pyridine solution. Absorbance of sample and standard panthothenic and solution 
of range $10 \mu \mathrm{g} / \mathrm{ml}$ - $50 \mu \mathrm{g} / \mathrm{ml}$ prepared from stock panthothenic acid was read on a spectronic spectrophotometer at a wavelength of $570 \mathrm{~nm}$. Panthothenic acid was calculated in $\mu \mathrm{g} / 100 \mathrm{~g}$.

\subsubsection{Determination of Cyanocobalamin (Vitamin B12)}

One gramme of each sample was weighed into a $250 \mathrm{ml}$ volumetric flask. $100 \mathrm{ml}$ of distilled water was added and spinned or shaken for $45 \mathrm{~min}$ and made up to mark with distilled water. The sample mixture was filtered into another $250 \mathrm{ml}$ beaker, rejecting the first $20 \mathrm{ml}$ that has been filtered. Another $20 \mathrm{ml}$ filtrate was collected. To the filtrate, $5 \mathrm{ml}$ of $1 \%$ Sodium Dithionite solution was added to decolorised the yellow colour. Standard cyanocobalamin solutions of range $0-10 \mu \mathrm{g} / \mathrm{ml}$ were prepared from stock cyanocobalamin. A sample blank made up to distilled water was also prepared. The absorbance of sample and standards was read at a wavelength of $445 \mathrm{~nm}$ on a spectronic 21D spectrophotometer.

\subsubsection{Caffeine Determination}

Five millilitres of sample was pipetted into a $250 \mathrm{ml}$ separating funnel, and $5 \mathrm{ml}$ of $1 \mathrm{M} \mathrm{NaOH}$ solution and 30 $\mathrm{ml}$ of chloroform were added. The funnel was stoppered and the content shaken for 5 minutes. The aqueous layer was discharged leaving the organic chloroform layer. Five millilitre of $1 \mathrm{M} \mathrm{NaOH}$ and $15 \mathrm{ml}$ of $0.1 \mathrm{M}$ $\mathrm{KMnO}_{4}$ solutions were added to the chloroform layer in the funnel and the whole mixture shaken for 10 minutes. The chloroform was charged into a $250 \mathrm{ml}$ Beaker containing $20 \mathrm{~g}$ of anhydrous magnesium sulphate to dry the extract. The chloroform was removed from extract by distillation at $80^{\circ} \mathrm{C}$. The residue was dissolve in $50 \mathrm{ml}$ of hot deionized water in a $100 \mathrm{ml}$ volumetric flask. Working standard of range 0 - $50 \mathrm{ppm}$ of caffeine solutions were prepared from $100 \mathrm{ppm}$ stock caffeine and treated similarly like sample. The absorbance of sample extract and caffeine standard solutions was read on a UV spectrophotometer at a wavelength of $274 \mathrm{~nm}$. Concentration of sample caffeine was determined from the calibration curve of standard caffeine solutions.

\section{Results and Discussion}

\subsection{Socio-Demographic Characteristics of Respondents}

Mean age of respondents was $23.1 \pm 4.6$ years, $79.2 \%$ were undergraduates and $51.1 \%$ were female. Majority (74.6\%) of respondents had ever taken energy drinks prior to the study, $42.4 \%$ reported consuming at least one can in a week, and $52.1 \%$ consumed one can at a sitting. Reasons for consumption were to increase: energy (48.2\%), mental alertness (18.6\%) and athletic performance.

\subsection{Physico-Chemical Characteristics of Energy Drink}

Table 1 shows the physico-chemical characteristics of energy drinks. There were significant differences in the titratable acidity and total solids value of the samples $(\mathrm{p}<0.05)$. Matador had the highest titratable acidity followed by Red Bull, while Emerge had the lowest value. Red Bull was highest in total solid followed by Matador, while Power horse had the least value.

The $\mathrm{pH}$ value of the energy drinks was low and in the acidic medium with Emerge having lowest value, and hence, most acidic. The Power horse value was not significantly different from that of Matador, but was significantly different from that of Emerge and Red Bull. The result obtained for the $\mathrm{pH}$ values of the drinks in this study was in line with the findings of [14] who quantified the acid content of commercial yoghurt drinks in Nigeria. Dental erosion is commonly caused by dietary factors, especially food or drinks that contain citric acid which may chelate as well as dissolve calcium ions [15] [16]. Beverages with low $\mathrm{pH}$ values generally have greater erosive effects on tooth structure. However, carbonated cola beverages, sports and energy drinks have been reported to have low $\mathrm{pH}$ an d high buffering capacity, sweetened with highly refined carbohydrates and contain additional additives which together with sugar substitutes can contribute to enamel surface dissolution [17] [18]. All the energy drinks evaluated had $\mathrm{pH}$ on opening below the critical $\mathrm{pH}$ (5.5) of enamel dissolution [14]. Their low $\mathrm{pH}$ values call for caution in their regular consumption.

\subsection{Nutrient Composition of Energy Drinks}

The result of the nutrient and energy content of the four commonly consumed energy drinks among students is as shown in Table 2(a). The total sugar content (glucose and sucrose) was relatively high and significantly 
Table 1. Physico-chemical characteristics of selected energy drinks (\%)

\begin{tabular}{cccc}
\hline \multirow{2}{*}{ Energy Drinks } & \multicolumn{3}{c}{ Parameter } \\
\cline { 2 - 4 } & Titratable Acidity (\%) & Total Solid (\%) & pH (25 $\mathbf{C})$ \\
\hline Power Horse & $7.93 \pm 0.07$ & $7.57 \pm 0.60$ & $3.63 \pm 0.25$ \\
Emerge & $7.57 \pm 0.60$ & $10.61 \pm 0.03$ & $3.36 \pm 0.08$ \\
Red Bull & $8.00 \pm 0.07$ & $11.42 \pm 0.31$ & $3.81 \pm 0.12$ \\
Matador & $8.28 \pm 0.08$ & $11.29 \pm 0.45$ & $3.66 \pm 0.03$ \\
\hline
\end{tabular}

*Values are means \pm Standard deviation of triplicate determinations. Can Size: Power Horse: 330 ml; Emerge: 250 ml; Red Bull: 250 ml; Matador: $330 \mathrm{ml}$.

Table 2. (a) Nutrient composition of selected energy drinks (/100 ml) ${ }^{*}$; (b) Nutrition information declared by manufacturers $(/ 100 \mathrm{ml})$.

(a)

\begin{tabular}{ccccc}
\hline & \multicolumn{4}{c}{ Energy Drink } \\
\cline { 2 - 5 } Parameter & P. Horse & Emerge & Red Bull & Matador \\
\cline { 2 - 5 } & $7.89 \pm 0.01$ & $7.77 \pm 0.01$ & $7.82 \pm 0.01$ & $7.84 \pm 0.05$ \\
Glucose $(\mathrm{g} /)$ & $23.74 \pm 0.09$ & $22.61 \pm 0.07$ & $23.03 \pm 0.07$ & $23.46 \pm 0.05$ \\
Sucrose $(\mathrm{g} /)$ & $0.22 \pm 0.01$ & $0.11 \pm 0.00$ & $0.28 \pm 0.03$ & $0.12 \pm 0.01$ \\
Ash $(\mathrm{g} /)$ & $2.50 \pm 0.01$ & $1.59 \pm 0.01$ & $1.84 \pm 0.01$ & $2.24 \pm 0.01$ \\
Vitamin $\mathrm{B}_{5}(\mathrm{mg} /)$ & $2.52 \pm 0.01$ & $1.57 \pm 0.02$ & $2.05 \pm 0.02$ & $2.64 \pm 0.02$ \\
Vitamin $\mathrm{B}_{6}(\mathrm{mg} /)$ & $1.85 \pm 0.03$ & $1.75 \pm 0.03$ & $1.71 \pm 0.03$ & $2.64 \pm 0.02$ \\
Vitamin $\mathrm{B}_{12}(\mu \mathrm{g} /)$ & $28.76 \pm 0.05$ & $24.19 \pm 0.09$ & $25.81 \pm 0.08$ & $27.80 \pm 0.17$ \\
Caffeine $(\mathrm{mg} /)$ & $48.89 \pm 0.28$ & $43.59 \pm 0.38$ & $44.83 \pm 0.29$ & $46.32 \pm 0.39$ \\
G. Energy $(\mathrm{kcal} /)$ & & &
\end{tabular}

*Values are means \pm Standard deviation of triplicate determinations. Can Size: Power Horse: 330 ml; Emerge: 250 ml; Red Bull: 250 ml; Matador: $330 \mathrm{ml}$

(b)

\begin{tabular}{ccccc}
\hline & \multicolumn{3}{c}{ Energy Drink } \\
\cline { 2 - 5 } Parameter & P. Horse & Emerge & Red Bull & Matador \\
\hline Carbohydrates $(\mathrm{g} /)$ & 10.7 & 10.0 & 11.3 & 10.9 \\
Vitamin $\mathrm{B}_{5}(\mathrm{mg} /)$ & 2.0 & 2.0 & 2.0 & 2.0 \\
Vitamin $\mathrm{B}_{6}(\mathrm{mg} /)$ & 2.0 & 0.6 & 2.0 & 2.0 \\
Vitamin $\mathrm{B}_{12}(\mu \mathrm{g} /)$ & 2.0 & 0.5 & 2.0 & 2.0 \\
Caffeine $(\mathrm{mg} /)$ & 32.0 & 30.0 & 30.0 & 30.0 \\
G. Energy $(\mathrm{kcal} /)$ & 45.0 & 42.0 & 45.0 & 46.0
\end{tabular}

Calorie contribution to energy intake of consumers of $250 \mathrm{ml}$ of selected energy drinks ranged from 105 kilocalories in Emerge to $122.23 \mathrm{kcal}$ in power Horse.

different in all samples $(\mathrm{p}<0.05)$. Power horse contained highest amount of total sugar $(31.63 \mathrm{~g} / 100 \mathrm{ml})$ while emerge contained lowest value with no statistically insignificant difference. Consumption of a can of Red Bull (250 ml) will deliver $19.6 \mathrm{~g}$ of glucose and $57.58 \mathrm{~g}$ sucrose, with total sugar content of $77.18 \mathrm{~g}$.

Energy contribution from $100 \mathrm{ml}$ of Power horse was significantly higher than that of other brands, followed by that of Matador. The gross energy content of Emerge and Red Bull were closely related, Red Bull being slightly higher. On the basis of can liquid content of $250 \mathrm{ml}$, various brands of the energy drinks can provide calories as follows: Power Horse 122.23 kilocalories, Emerge 108.98 kilocalories, Red Bull 112.08 kilocalories, and Matador 115.80 kilocalories of energy. On liquid content only, Power Horse (330 ml) can provide 161.34 kilocalories while Matador (330 ml) can provide 152.86 kilocalories of energy.

$\mathrm{B}$ Vitamins are touted as ingredients necessary to convert the added sugar to energy, hence, the B vitamins are commonly used as ingredients in energy drinks; and the content varies in brands. The values of vitamins $\mathrm{B}_{5}, \mathrm{~B}_{6}$ and $B_{12}$ of the four samples of energy drinks were significantly different from each other $(p<0.05)$. Power Horse had the highest value of vitamin B5 followed by Matador, while Emerge had the least. Matador was 
highest in vitamin B6 and B12 followed by Power Horse. A $250 \mathrm{ml}$ can of energy drinks can deliver more than RDA for vitamins B5, B6 and B12 which is $5 \mathrm{mg}, 1.3 \mathrm{mg}$ and $2.4 \mu \mathrm{g}$ respectively [19].

Long-term exposure of the body to excess of simple sugars is associated with the development of obesity and insulin resistance. Over time, in many individuals the beta cells become unable to secrete sufficient insulin to maintain normal blood glucose levels, leading to the development of diabetes [20]. Regular consumption of two or more cans of energy drinks at a sitting or long term usage may result in high blood glucose level, increase risk of diabetes and obesity.

Table 2(b) shows the nutrition information as declared by manufacturers. The energy content declared by the manufacturers was closely related, though this study's results were slightly higher. The energy content of Power Horse and Emerge was significantly higher than what was declared on the cans $(p<0.05)$. The selected $\mathrm{B}$-vitamin values were lower than that determined in the laboratory for Power Horse and Matador for $\mathrm{B}_{5}$ and $\mathrm{B}_{6}$, but higher than those for Emerge and Red Bull. The reported value of $B_{6}$ and $B_{12}$ for Emerge were significantly lower than their determined value.

The declared values for caffeine of the selected energy drinks were significantly higher than determined values $(\mathrm{p}<0.05)$. This observation might have resulted in the methods of analysis which was not contained on the can label.

Table 3 shows the mean concentrations of heavy metals in the different brands of canned energy drinks. Significant differences existed between the heavy metals' values in the four samples $(\mathrm{p}<0.05)$. The observed variation in the heavy metal content could be due to their heterogeneity, sources of raw materials, origin, manufacturing and packing processes. The highest mean level $(\mu \mathrm{g} / 100 \mathrm{ml})$ of lead $(0.48)$, cadmium $(0.02)$, arsenic $(0.71)$, chromium (60.89) and mercury (0.07) in the four energy drinks samples were observed in Emerge, Power Horse and Matador, Emerge, Matador, and Red bull respectively.

Heavy metal content of carbonated soft drinks were reported for lead and cadmium as 0.04 and $0.002 \mathrm{ppm}$, respectively, while 0.06 and $0.003 \mathrm{ppm}$ were reported for lead and cadmium content of fruit juice in Nigeria [21]. In Turkey, Bingöl et al. [22] reported the mean values of lead, cadmium and arsenic as: 0.029; 0.005; and 0.037 $\mathrm{mg} / \mathrm{kg}$ and respectively. The reported values for the heavy metals are significantly lower than the ones obtained in this study. The chromium content of the energy drinks was high, higher than the recommended value of adequate intake of this metal. In a similar study by Iwegbue [23], high chromium content in canned beer above drinking water permissible level was also reported.

Lead can cause kidney damage and renal failure, damage to haemoglobin production, and to the nervous and gastric systems, while other metals can cause nephritis, anuria and extension of lesions in the kidney [24]. The permissible level for lead and cadmium in drinking water is $0.1 \mathrm{mg} / \mathrm{L}$ and $0.005 \mathrm{mg} / \mathrm{L}$ respectively [25]. Adequate Intake (AI) for chromium is $35 \mu \mathrm{g} /$ day for males aged 19 - 50 years and $25 \mu \mathrm{g} /$ day for females of the same age group [26].

The lead content of the four samples were below the permissible limit while the cadmium and chromium content was above the permissible level for drinking water, hence, caution has to be taken in consumption of energy drinks, as excessive intake can lead to increased level of heavy metal accumulation in the body. Heavy metal accumulation can predispose people to non communicable diseases such as cardiovascular diseases and cancers of various types.

\section{Conclusion}

Sugar and caffeine are the primary ingredients common in energy drinks and they are present at various levels of

Table 3. Heavy metal content of energy drinks $(\mu \mathrm{g} / 100 \mathrm{ml})$.

\begin{tabular}{ccccc}
\hline \multirow{2}{*}{ Metal } & \multicolumn{2}{c}{ Energy Drink } & Red Bull & Matador \\
\cline { 2 - 5 } & P. Horse & Emerge & 0.16 & 0.24 \\
Lead & 0.46 & 0.48 & 0.01 & 0.02 \\
Cadmium & 0.02 & 0.01 & 0.22 & 0.21 \\
Arsenic & 0.29 & 0.71 & 53.43 & 60.89 \\
Chromium & 54.98 & 54.51 & 0.07 & ND \\
Mercury & ND & ND & & \\
\hline
\end{tabular}

Values are means \pm Standard deviation of triplicate determinations. ND = Not detected at microgramme level. Can Size: Power Horse: 330 ml; Emerge: $250 \mathrm{ml}$; Red Bull: $250 \mathrm{ml}$; Matador: $330 \mathrm{ml}$. 
concentrations in the brands. All the four energy drinks had $\mathrm{pH}$ well below the $\mathrm{pH} 5.5$ of dissolution of enamel. Improper consumption and overuse of energy drinks over a long period of time may cause additional calorie intake of consumers that may not be accounted for, thereby leading to additional weight on consumers, as well as dental erosion (especially on immature teeth). Excess of refined sugars as used in energy drinks and high level of heavy metals may serve as risk factors for non communicable diseases such as diabetes, obesity, coronary heart disease and cancers if consumed excessively on regular basis.

\section{References}

[1] Alford, C., Cox, H. and Wescott, R. (2001) The Effects of Red Bull Energy Drink on Human Performance and Mood. Amino Acids, 21, 139-150. http://dx.doi.org/10.1007/s007260170021

[2] Brian (2004) Energy Drinks: Ingredients \& Dangers. CitynetMagazine.com, November 23rd, 2004.

[3] Salamon, M. (2011) Study: Alcohol-Energy Drink Combo Riskier than Booze Alone. USA Today. http://yourlife.usatoday.com/health/story/2011/04/Study-Alcohol-energy-drink-combo-riskier-than-booze-alone

[4] Warburton, D.M., Bersellini, E. and Sweeney, E. (2001) An Evaluation of a Caffeinated Taurine Drink on Mood, Memory and Information Processing in Healthy Volunteers without Caffeine Abstinence. Psychopharmacology, 158, 322-328. http://dx.doi.org/10.1007/s002130100884

[5] Smith, H.J., Cotton, J.R., Hughes, S.C. and Rogers, P.J. (2004) Mood and Cognitive Performance Effects of Energy Drink Constituents: Caffeine, Glucose and Carbonation. Nutritional Neuroscience, 7, 127-139. http://dx.doi.org/10.1080/10284150400003041

[6] Bevnet (2007) Beverage Reviews. www.bevnet.com/reviews/categories.asp

[7] Higgins, J.P., Tuttle, T.D. and Higgins, C.L. (2010) Energy Beverages: Content and Safety. Mayo Clinic Proceedings, 85, 1033-1041. http://dx.doi.org/10.4065/mcp.2010.0381

[8] U.S. Department of Health and Human Services, U.S. Department of Agriculture (2007) Dietary Guidelines for Americans, 2005. www.healthierus.gov/dietaryguidelines/

[9] Egger, G. and Swinburn, B. (1997) An Ecological Approach to the Obesity Pandemic. British Medical Journal, 315, 477-480. http://dx.doi.org/10.1136/bmj.315.7106.477

[10] Bray, G.A., Nielsen, S.J. and Popkin, B.M. (2004) Consumption of High-Fructose Corn Syrup in Beverages May Play a Role in the Epidemic of Obesity. The American Journal of Clinical Nutrition, 79, 537-543.

[11] West, N.X., Hughes, J.A. and Addy, M. (2000) Erosion of Dentin and Enamel in Vitro by Dietary Acids: The Effect of Temperature, Acid Character, Concentration and Exposure Time. Journal of Oral Rehabilitation, 27, 875-880. http://dx.doi.org/10.1046/j.1365-2842.2000.00583.x

[12] AOAC (2005) Official Methods of Analysis of Association of Official Analytical Chemists. Garthersburg, Washington DC.

[13] Essien, A.I., Ebana, R.U.B. and Udo, H.B. (1992) Chemical Evaluation of Pod and Pulp of the Fluted Pumpkin (Telfaira occidentalis) Fruit. Food Chemistry, 45, 175-178. http://dx.doi.org/10.1016/0308-8146(92)90110-N

[14] Bamise, C.T. and Bamise, O.F. (2008) Quantifying the Acidic Content of Commercial Yoghurt Drinks in Nigeria. The Internet Journal of Dental Science, 6, 16.

[15] Imfeld, T. (1996) Dental Erosion: Definition, Classification and Links. European Journal of Oral Science, 104, 151155. http://dx.doi.org/10.1111/j.1600-0722.1996.tb00063.x

[16] Jarvinen, V.K., Rytomaa, I.I. and Heinonen, O.P. (1991) Risk Factors in Dental Erosion. Journal of Dental Research, 70, 942-947. http://dx.doi.org/10.1177/00220345910700060601

[17] Von Fraunhofer, J.A. and Rogers, M.M. (2005) Effects of Sports Drinks and Other Beverages on Dental Enamel. General Dentistry, 53, 28-31.

[18] Moazzez, R., Smith, B.G.N. and Bartlett, D.W. (2000) Oral pH and Drinking Habit during Ingestion of a Carbonated Drink in a Group of Adolescents with Dental Erosion. Journal of Dentistry, 28, 395-397. http://dx.doi.org/10.1016/S0300-5712(00)00020-8

[19] Food and Nutrition Board (2001) Dietary Reference Intakes for Vitamin A, Vitamin K, Arsenic, Boron, Chromium, Copper, Iodine, Iron, Manganese, Molybdenum, Nickel, Silicon, Vanadium, and Zinc. National Academy Press, Washington DC.

[20] Tappy, L., Lê, K.A., Tran, C. and Paquot, N. (2010) Fructose and Metabolic Diseases: New Findings, New Questions. Nutrition, 26, 1044-1049. http://dx.doi.org/10.1016/j.nut.2010.02.014

[21] Onianwa, P.C., Adetola, I.G., Iwegbue, C.M.A., Ojo, M.F. and Tella, O.O. (1999) Trace Heavy Metals Composition of Some Nigerian Beverages and Food Drinks. Food Chemistry, 66, 275-299. 
http://dx.doi.org/10.1016/S0308-8146(98)00257-X

[22] Bingol, M., Yentur, G., Er, B. and Oktem, A.B. (2010) Determination of Some Heavy Metal Levels in Soft Drinks from Turkey Using ICP/OES Method. Czech Journal of Food Sciences, 28, 213-216.

[23] Iwegbue, C.M.A. (2010) Composition and Daily Intakes of Some Trace Metals from Canned Beers in Nigeria. J. Inst. Brew. 116, 312-315. http://dx.doi.org/10.1002/j.2050-0416.2010.tb00436.x

[24] Abou-Arab, A.A.K., Ayesh, A.M., Amra, H.A. and Naguib, K. (1999) Characteristic Levels of Some Pesticides and Heavy Metals in Imported Fish. Food Chem., 57, 487-492 http://archives.cnn.com/2001/HEALTH/diet.fitness/05/29/energy.drinks.02/

[25] Standard Organization of Nigeria (2003) Safe Drinking Water Regulation. Standard Organization of Nigeria, Abuja.

[26] Food and Nutrition Board (2001) Dietary Reference Intakes for Vitamin A, Vitamin K, Arsenic, Boron, Chromium, Copper, Iodine, Iron, Manganese, Molybdenum, Nickel, Silicon, Vanadium, and Zinc. National Academy Press, Washington DC. 
Scientific Research Publishing (SCIRP) is one of the largest Open Access journal publishers. It is currently publishing more than 200 open access, online, peer-reviewed journals covering a wide range of academic disciplines. SCIRP serves the worldwide academic communities and contributes to the progress and application of science with its publication.

Other selected journals from SCIRP are listed as below. Submit your manuscript to us via either submit@scirp.org or Online Submission Portal.
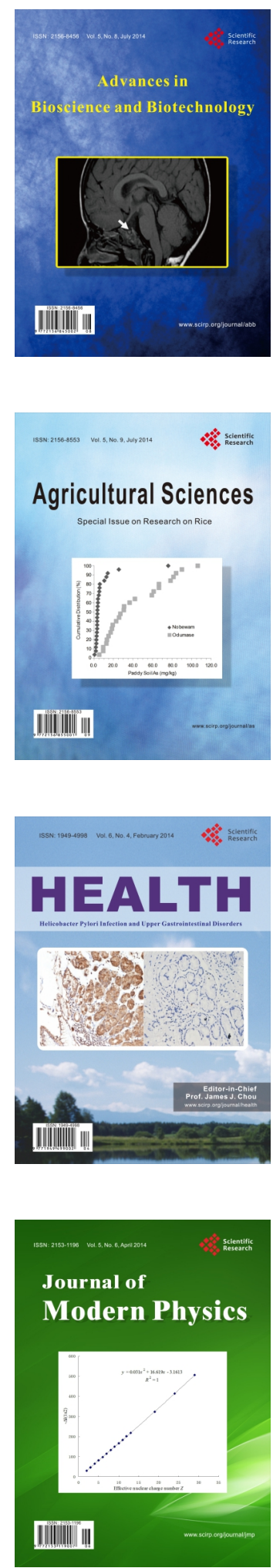
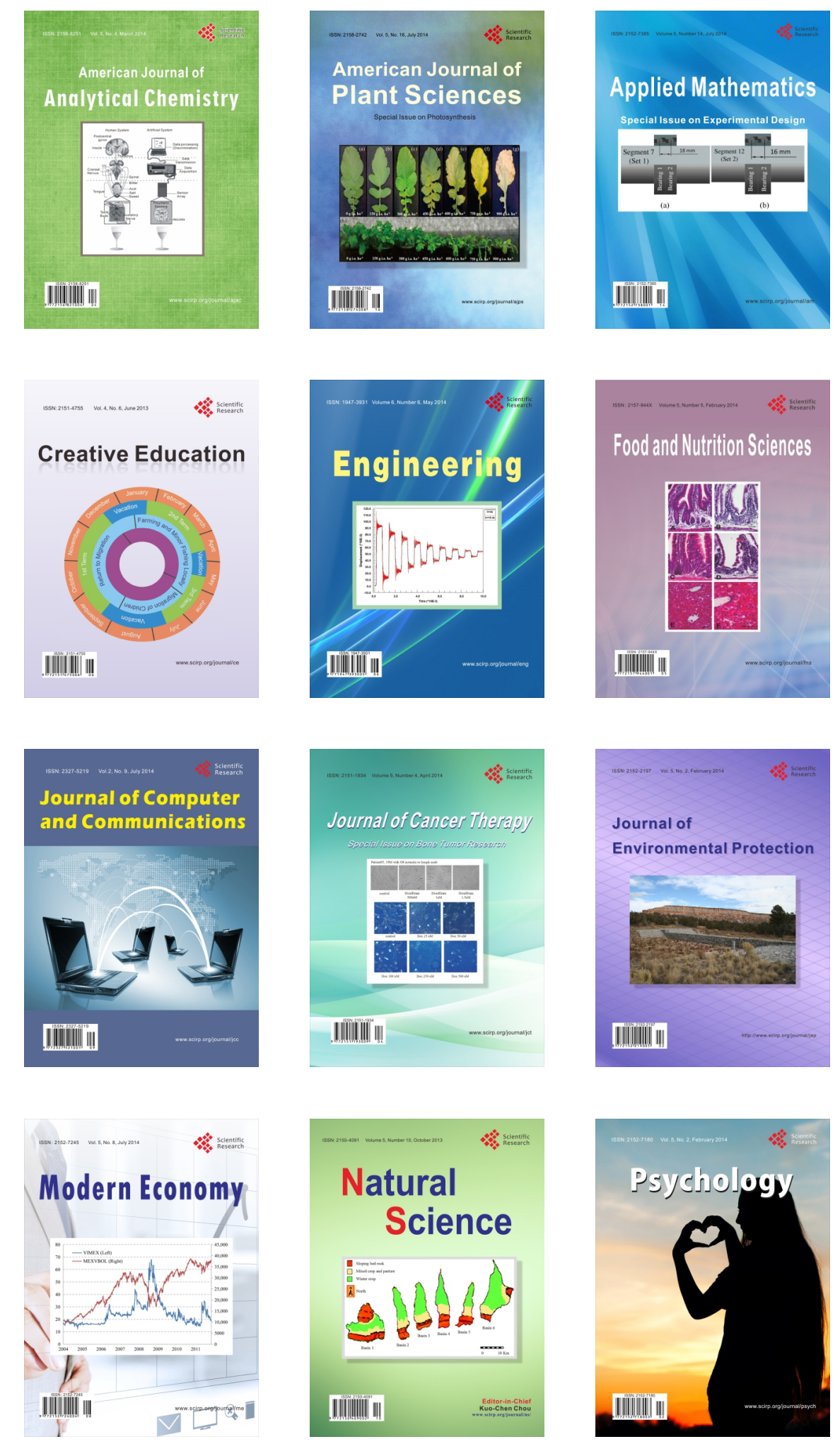